\title{
A Prospective Study To Evaluate The Etiology \& Continuum of Management Protocol of Postpartum Haemorrhage
}

\author{
Abhilasha Singh ${ }^{1}$, Smiti Nanda $^{2}$ \\ I(PGT, Department Of Obst. \& Gynae, Pt. B.D. Sharma PGIMS, Rohtak, India) \\ ${ }_{2}^{2}$ (Professor \& Head, Department Of Obst. \& Gynae, Pt. B.D. Sharma PGIMS, Rohtak, India)
}

\begin{abstract}
Postpartum hemorrhage (PPH) is one of the leading causes of death in women. Women who deliver after 20 weeks of gestation are specially at risk for PPH and its sequelae. This study was undertaken to evaluate the causes and risk factors associated with PPH, various techniques/modalities used to control PPH and to assess the impact of PPH on the maternal morbidity and mortality. This prospective study was carried out over a period of six months from September 2014 to February 2015 in the Dept. of Obstetrics and Gynaecology, Pt. B.D. Sharma PGIMS, Rohtak. All the women who had PPH after vaginal delivery or caesarean section along with the cases of PPH referred from outside were included. Detailed history was taken. General and local examinations were done to assess the cause of PPH. The patients were followed up in the hospital for all morbidity complications. Incidence of PPH in present study was $2.73 \%$. Maximum number of cases $(n=65,48.14 \%)$ were among age group of 20-24 years with parity $P 1 \quad(n=62,45.92 \%), P 2(n=45$, $33.33 \%), P 3(n=19,14.07 \%)$ and $P 4(n=7,5.18 \%)$. Anaemia was found to be most common $(n=44,32.5 \%)$ risk factor followed by placenta praevia $(n=14,10.3 \%)$ and previous LSCS $(n=10,7.40 \%)$. Pre-eclampsia was risk factor among 4 cases. Primary PPH is an extremely challenging obstetric emergency associated with significant morbidity and still one of leading causes of maternal mortality. Early recognition and treatment are essential to ensure the best outcome from this life threatening condition. Though hysterectomy is the definitive treatment in women with severe PPH but in patients who desire future fertility, medical management, mechanical methods like uterine compression, uterine packing, uterine tamponade and surgical procedures like uterine artery ligation and uterine compression sutures are effective methods.
\end{abstract}

Keywords: Continuum, Etiology, Management, Postpartum Haemorrhage, PPH

\section{Introduction}

Pregnancy and childbirth are natural functions from which most of the women recover without complication. However, one of the most common physiologic complications is obstetric hemorrhage. Postpartum hemorrhage (PPH) is one of the leading causes of death in women who deliver after 20 weeks of gestation. ${ }^{1}$ It is defined by the World Health Organization (WHO) as postpartum blood loss in excess of $500 \mathrm{ml}$, it is a clinical diagnosis that encompasses excessive blood loss after delivery of the baby from a variety of sites: uterus, cervix, vagina and perineum. Blood loss during the first 24 hours after delivery is known as primary $\mathrm{PPH}$, whereas blood loss from 24 hours up to 6 weeks after delivery is termed late or secondary PPH. The bleeding is also classified according to its site. Hence primary PPH is also classified as either placental or extraplacental bleeding. ${ }^{2}$

Postpartum haemorrhage ( $\mathrm{PPH})$ is a life threatening situation and an obstetrician's nightmare. It remains a major cause of maternal morbidity and mortality worldwide, especially in developing countries. There are 600,000 maternal deaths reported worldwide every year and $99 \%$ of these occur in developing countries. Postpartum haemorrhage accounts for $25 \%$ of the mortalities in developing world. The prevalence of PPH in India is $23 \%$. In developing countries, where most births occur in homes or local clinics, the interventions needed to treat PPH like emergency referrals, obstetric care, blood transfusion, and surgery are simply out of reach for the majority of the women. Delayed diagnosis and poor management of PPH are associated with increased mortality and morbidity.,

PPH has many potential causes, but Uterine atony is the most common cause, responsible for $75-90 \%$ of cases of PPH followed by genital tract trauma, retained tissue and coagulopathy. ${ }^{3}$ In a recent randomized trial in the United States, birth weight, labor induction and augmentation, chorioamnionitis, magnesium sulfate use, and previous PPH were all positively associated with increased risk of PPH. ${ }^{5}$

Uterine atony is defined as failure of myometrium to contract and retract following delivery. ${ }^{6}$ Powerful and effective myometrial contractions are vital to arrest bleeding. Uterine atony in contrary, the uterus is soft and 'boggy' with presence of excessive bleeding from genital tract. A prompt recognition followed by uterine massage and administration of uterotonic agents often arrest the bleeding. However, in the presence of already well contracted uterus, any persistent bleeding should prompt exploration for other causes of PPH such as retained placental fragments or genital tract injuries. 
A Prospective Study To Evaluate The Etiology \& Continuum Of Management Protocol ...

Damage to the genital tract may occur spontaneously or through manipulations used to deliver the baby. Trauma may also occur following very prolonged or vigorous labor, especially if the patient has relative or absolute cephalopelvic disproportion and the uterus has been stimulated with oxytocin or prostaglandins. Cesarean delivery results in twice the average blood loss of vaginal delivery.

Uterine rupture is most common in patients with previous cesarean delivery scars. Routine transvaginal palpation of such scars is no longer recommended. Any uterus that has undergone a procedure resulting in a total or thick partial disruption of the uterine wall should be considered at risk for rupture in a future pregnancy. This admonition includes fibroidectomy; uteroplasty for congenital abnormality; cornual or cervical ectopic resection; and perforation of the uterus during dilatation, curettage, biopsy, hysteroscopy, laparoscopy, or intrauterine contraceptive device placement.

Preexisting abnormalities of the clotting system, such as familial hypofibrinogenemia and von Willebrand disease, may occur and should be considered. Acquired abnormalities are Disseminated Intravascular Coagulation (DIC) related to abruptio placentae, HELLP syndrome, intrauterine fetal demise, amniotic fluid embolism, and sepsis. Fibrinogen levels are markedly elevated during pregnancy, and a fibrinogen level that would be in the reference range in the nonpregnant state should be viewed with suspicion in the aforementioned clinical scenarios.

At term, the estimated blood flow to the uterus is $500-800 \mathrm{~mL} / \mathrm{min}$, which constitutes $10-15 \%$ of cardiac output. Most of this flow traverses the low-resistance placental bed. The uterine blood vessels that supply the placental site traverse a weave of myometrial fibers. As these fibers contract following delivery, myometrial retraction occurs. Retraction is the unique characteristic of the uterine muscle to maintain its shortened length following each successive contraction. The blood vessels are compressed and kinked by this crisscross latticework, and, normally, blood flow is quickly occluded. This arrangement of muscle bundles has been referred to as the "living ligatures" or "physiologic sutures" of the uterus.

Medical management is starts with uterotonics to control PPH. Oxytocin is the drug of choice. Ergot alkaloids are recommended in patients at high risk of PPH but contraindicated in patients with hypertension and heart disease. Prostaglandins are second line drugs. Misoprostol can be administered by sublingual,vaginal or rectal routes. When medical management has failed, surgery is the only life-saving option. In almost all cases in which surgical management is chosen after medical management has failed, not attempting surgery would lead to maternal morbidity and mortality.

\section{Aims And Objects}

Thus, the present study was undertaken to evaluate the causes and risk factors associated with PPH, study the various techniques/modalities used to control PPH and to assess the impact of PPH on the maternal morbidity and mortality.

\section{Materials And Methods}

This prospective study was carried out over a period of six months from September 2014 to February 2015 in the Dept. of Obstetrics and Gynaecology, Pt. B.D. Sharma PGIMS, Rohtak. All the women who had PPH after vaginal delivery or caesarean section in Pt. B.D. Sharma PGIMS, Rohtak along with the cases of PPH referred from outside during the study period were included in the study. Detailed history regarding gravidity, parity, gestational age, mode of delivery, place of delivery and other concomitant conditions was recorded after taking written consent. A quick general physical examination was done to assess the degree of hemorrhage. Uterine tone was checked and local examination was done to assess the cause of PPH. Placenta was also examined. Hemoglobin, BT, CT and blood group were checked. Active management of the third stage of labour (AMTSL) was done in all women delivering at our Institution. Estimation of blood loss was made via subjective as well as objective assessment. Subjective measures included amount of blood collected in PPH bags, estimation of blood clots and blood in the suction bottle whereas objective assessment was made via serial measurement of the reduction in hemoglobin level or evaluation of the need for blood transfusions. In patients referred from outside estimation of blood loss was done by history, general examination and local examination.

Diagnosed patients were managed as per the cause of PPH and hospital protocol. Call for help was given. Rapid initial assessment of the patient was conducted, followed by evaluation of airway breathing circulation along with necessary interventions. Foleys catheter was inserted to monitor urine output. Intravenous crystalloids were started using two large bore IV Cannulas. Blood was arranged as per requirement. For atonic PPH, uterotonics (oxytocin, carboprost, misoprostol) was used alone or in combination. Uterine massage along with oxytocin administration (10U IM \& $40 \mathrm{U}$ in $500 \mathrm{ml} \mathrm{NS}, 125 \mathrm{ml} / \mathrm{hr}$ ) were given. If the uterus remains atonic, bimanual massage was started along with administration of $\mathrm{PGF}_{2} \alpha$ (i.m. or intramyometrial,) 250 mcg every 15 20 mins upto 8 doses. Tab misoprostol were given per rectal $(800-1000 \mathrm{mcg})$. If uterus failed to contract inspite of uterotonics and bimanual massage, intrauterine tamponade with condom was done. In patients not responding to these measures, surgical management was the next option. The hospital protocol was followed i.e. stepwise 
A Prospective Study To Evaluate The Etiology \& Continuum Of Management Protocol ...

uterine devascularistion, brace suturing, which, if required was followed by Internal iliac ligation/hysterectomy. For patients who had traumatic PPH, exploration and repair of cervical and vaginal lacerations and tears was done. In case of retained placental bits, manual removal of products was done. Hysterectomy was the ultimate life saving surgery if patient do not respond to conservative management.

The management of PPH after cesarean delivery also was done according to cause and as per hospital protocol. In case of uterine atony, direct bimanual compression along with administration of uterotonics (oxytocin, 15-methyl prostaglandin $\mathrm{F}_{2} \alpha$, misoprostol) was done. Retained tissues were removed under direct visualization. Repair of extended incision was done. If required, balloon tamponade, stepwise uterine devascularisation and brace suturing was done. Hysterectomy was done if bleeding continues after using all the measures. The patients were followed up in the hospital for all morbidity complications. Repeat investigations viz. $\mathrm{Hb}$ etc. was done. Condition at discharge was recorded.

Ethical clearance was obtained from the Institutional Ethics Committee, Pt. B.D. Sharma PGIMS, Rohtak and confidentiality was maintained.

\section{Statistical analysis}

All the results were statistically analyzed by using Chi-square method. Conclusion was drawn regarding causes, risk factors, treatment modalities and outcome of $\mathrm{PPH}$ patients. A p value of $<0.05$ was considered as significant.

\section{Results}

Total number of deliveries took placed during the study period were 4933. Results showed that PPH was present in 135 patients with an incidence of 2.73\%. Most common age group was 20-24 yrs. Maximum number of cases were P1 ( $\mathrm{n}=62,45.92 \%)$ followed by P2 $(\mathrm{n}=45,33.33 \%)$ and P3 $(\mathrm{n}=19,14.07 \%)$ and P4 $(\mathrm{n}=7$, $5.18 \%$ ). With regard to socio economic status, $56 \%$ ) were from lower middle status and $29.62 \%$ from middle socio economic status. Out of total 135 cases, 85 (62.96\%) cases had compensated haemorrhage followed by 28 cases $(20.74 \%)$ of mild degree. Nine $(6.66 \%)$ cases had moderate degree haemorrhage while $13(9.62 \%)$ of cases were found to have severe degree of haemorrhage. Total $87(64.44 \%)$ patients were delivered inside the hospital out of which $76(87.35 \%)$ passed into spontaneous labour and $11(12.64 \%)$ were induced. Forty eight $(35.5 \%)$ cases delivered outside our hospital and were later referred to our hospital.

Table:1 Association between Type of PPH with place of delivery, type of labour and mode of delivery

\begin{tabular}{|c|c|c|c|c|c|c|c|}
\hline & Atonic & Traumatic & $\begin{array}{c}\text { Atonic }+ \\
\text { Traumatic }\end{array}$ & $\begin{array}{l}\text { Retained } \\
\text { Placenta } \\
\text { / Rpocs }\end{array}$ & $\begin{array}{c}\text { Inversion } \\
\text { Uterus }\end{array}$ & $\begin{array}{l}\text { Chi-Square } \\
\text { Value }\end{array}$ & $\begin{array}{c}\mathrm{P} \\
\text { Valve }\end{array}$ \\
\hline Inborn & 72 & 6 & 5 & 1 & 0 & $\mathrm{X}^{2}=45.9$ & 0.001 \\
\hline Outborn & 12 & 17 & 11 & 9 & 2 & & \\
\hline $\begin{array}{l}\text { Sontaneous } \\
\text { Labour }\end{array}$ & 61 & 6 & 5 & 0 & 0 & $X^{2}=1.295$ & 0.73 \\
\hline $\begin{array}{l}\text { Induced } \\
\text { Labour }\end{array}$ & 11 & 0 & 0 & 1 & 0 & & \\
\hline $\begin{array}{l}\text { Caesarean } \\
\text { Section }\end{array}$ & 46 & 2 & 0 & 1 & 0 & $\mathrm{X}^{2}=37.8$ & 0.0001 \\
\hline $\begin{array}{l}\text { Vaginal } \\
\text { Delivery }\end{array}$ & 33 & 20 & 12 & 9 & 2 & & \\
\hline $\begin{array}{l}\text { Assisted } \\
\text { Vaginal } \\
\text { Delivery }\end{array}$ & 2 & 1 & 3 & 0 & 0 & & \\
\hline Laparotomy & 3 & 0 & 1 & 0 & 0 & & \\
\hline Anaemia & 20 & 12 & 5 & 4 & 2 & $\mathrm{X}^{2}=13.72$ & 0.318 \\
\hline P.Praevia & 13 & 1 & 0 & 0 & 0 & & \\
\hline P.Accreta & 2 & 0 & 0 & 0 & 0 & & \\
\hline Twins & 8 & 0 & 0 & 0 & 0 & & \\
\hline
\end{tabular}

It is evident from Table-1 that all types of PPH were more common in spontaneous labour than Induced labour. Maximum numbers of cases were atonic cases for both spontaneous labour and Induced labour. But this association was not found to be statistically significant $(\mathrm{p}=0.455)$. Maximum number of cases $(\mathrm{n}=75$, $55.55 \%)$ were delivered by vaginal delivery followed by Caesarean section $(n=50,37.03 \%)$. Among atonic cases 46 cases followed caesarean section while 33 cases were following vaginal delivery. Traumatic cases were 
A Prospective Study To Evaluate The Etiology \& Continuum Of Management Protocol ...

more after vaginal delivery (20) than any other method. Also combined atonic \& traumatic and Retained placenta/RPOCs were more after vaginal deliveries. This association was found to be statistically significant $(\mathrm{p}=0.0001)$. Anaemia was found to be most common $(n=44,32.5 \%)$ risk factor among cases, followed by placenta praevia $(n=14,10.3 \%)$ and previous $\operatorname{LSCS}(n=10,7.40 \%)$. Twins and Induction of labour were found among 8 patients each. Abruptio was found to be risk factor in 5 cases and Pre-eclampsia was among 4 cases. In 22 cases there were cervical or vaginal tear while in 9 cases there were no risk factor found. Anaemia was found to be associated with all types of PPH. Among atonic cases maximum cases were anaemic (20) followed by placenta praevia (13). For traumatic PPH also maximum numbers of cases were anaemic (12). Only 1 traumatic PP H case had placenta praevia. Placenta accreta and twins were found to be associated with atonic PPH only. But this association was not statistically significant $(\mathrm{p}=0.318$.)

Anaemia was found among 59(43.70\%) patients followed by RICU transfer of $7(5.18 \%)$ cases and wound sepsis among $6(4.44 \%)$ cases. Two $(1.48 \%)$ patients had DIC and $3(2.22 \%)$ had renal failure.

Table-2 Distribution of Mortality

\begin{tabular}{|c|c|c|c|c|c|c|c|c|}
\hline $\begin{array}{l}\text { Sr. } \\
\text { no }\end{array}$ & $\begin{array}{l}\text { Age } \\
\text { (yrs) }\end{array}$ & Inborn/outborn & $\begin{array}{l}\text { Type of } \\
\text { delivery }\end{array}$ & $\begin{array}{c}\text { Cause of } \\
\text { PPH }\end{array}$ & management & $\begin{array}{c}\text { Blood } \\
\text { transfusion }\end{array}$ & $\begin{array}{l}\text { Delivery- } \\
\text { death } \\
\text { interval }\end{array}$ & Cause of death \\
\hline 1 & 24 & inborn & LSCS & Atonic & hysterectomy & $1 \mathrm{pcv}$ & 1day & $\begin{array}{l}\text { Hypovolumic } \\
\text { shock }\end{array}$ \\
\hline 2 & 24 & outborn & FTVD & $\mathrm{A}+\mathrm{T}$ & $\begin{array}{c}\text { Balloon } \\
\text { tamponade }\end{array}$ & & Oday & $\begin{array}{l}\text { Hypovolumic } \\
\text { shock }\end{array}$ \\
\hline 3 & 27 & inborn & LSCS & Atonic & $\begin{array}{c}\text { Balloon } \\
\text { tamponade }\end{array}$ & $1 \mathrm{pcv}$ & 15days & Renal failure \\
\hline 4 & 22 & outborn & FTVD & $\mathrm{A}+\mathrm{T}$ & Hysterectomy & 4pcv 4ffp & 7days & Renal failure \\
\hline 5 & 23 & outborn & PTVD & $\begin{array}{l}\text { Retained } \\
\text { Tissue }\end{array}$ & Poc removed & 4ffp 2prp & 1day & $\begin{array}{l}\text { Hypoluvic } \\
\text { shock }\end{array}$ \\
\hline
\end{tabular}

There were 5 mortalities occurred in present study. Out of 5 mortalities 3 were outborn and 2 cases were delivered inside the institute. The common mode of delivery was vaginal delivery and cause of PPH was Atonic in 2 cases while Atonic +Traumatic was also in 2 cases. Two patients were managed by Balloon tamponade along with uterotonics while in 2 patients hysterectomy was done. The common cause of death was hypovolumic shock followed by renal failure. (Table-2)

Table - 3 Association between time of death during delivery and type of PPH

\begin{tabular}{|c|c|c|c|c|c|c|c|}
\hline \multirow{2}{*}{$\begin{array}{l}\text { Delivery } \\
\text { death time } \\
\text { interval }\end{array}$} & \multicolumn{5}{|c|}{ Type of PPH } & \multirow{2}{*}{$\begin{array}{c}\text { Chi-square } \\
\text { value }\end{array}$} & \multirow{2}{*}{$\begin{array}{c}\text { p-value } \\
0.735\end{array}$} \\
\hline & Atonic & Traumatic & $\begin{array}{l}\text { Atonic+ } \\
\text { traumatic }\end{array}$ & $\begin{array}{c}\text { Retained } \\
\text { placenta/ } \\
\text { RPOCs }\end{array}$ & $\begin{array}{c}\text { Inverted } \\
\text { uterus }\end{array}$ & & \\
\hline$<12$ hours & 2 & 0 & 0 & 0 & 0 & & \\
\hline $\begin{array}{c}>12-<24 \\
\text { hours }\end{array}$ & 0 & 0 & 1 & 1 & 0 & & \\
\hline $\begin{array}{c}>24 \text { hours- } 7 \\
\text { days }\end{array}$ & 0 & 0 & 1 & 0 & 0 & & \\
\hline
\end{tabular}

It is evident from table -3 that two patients expired due to atonic PPH within $12 \mathrm{hrs}$ of delivery. Two patients expired due to atonic + traumatic PPH and one patient expired due to retained placenta.

Table - 4 Association between time of death during delivery and place

\begin{tabular}{|c|c|c|c|c|}
\hline \multirow{2}{*}{$\begin{array}{c}\text { Delivery Death Time } \\
\text { Interval }\end{array}$} & \multicolumn{2}{|c|}{ Place Of Death } & \multirow{2}{*}{$\begin{array}{c}\text { Chi-Square Value } \\
\mathrm{X}^{2}=0.417\end{array}$} & \multirow{2}{*}{$\begin{array}{c}\text { P Value } \\
0.811\end{array}$} \\
\hline & Pgims & Referred From Outside & & \\
\hline$<12$ Hours & 1 & 1 & & \\
\hline$>12-<24$ Hours & 1 & 1 & & \\
\hline$>24$ Hours- 7 Days & 0 & 1 & & \\
\hline
\end{tabular}

Table-4 shows association between time of death during delivery and place of delivery. It is clear from above table that in PGIMS 1 patient died within 12 hours of delivery and 1 during $12-24$ hours of delivery. No patient died between $1-7$ days who had delivery in PGIMS. For patients who had delivery outside of PGIMS 1 patient died within 12 hours of delivery, 1 between $12-24$ hours and 1 patient died between $1-7$ days of delivery. 
A Prospective Study To Evaluate The Etiology \& Continuum Of Management Protocol ...

Table - 5 Management of PPH

\begin{tabular}{|l|c|c|}
\hline & Successful & $\begin{array}{c}\text { Followed By Another } \\
\text { Method }\end{array}$ \\
\hline Medical Method & 53 & 47 \\
\hline Cx/Vag Wall Tear Repair & 23 & \\
\hline Drainage Of Vulval Hematoma & 11 & \\
\hline Mrp & 7 & \\
\hline Removal Of Rpocs & 3 & \\
\hline Reposition Of Uterus & 2 & 8 \\
\hline Balloon Tamponade & 17 & 3 \\
\hline Uterine Artery Ligation & 9 & 2 \\
\hline B-Lynch Sutures & 8 & \\
\hline Hysterectomy & 8 & \\
\hline
\end{tabular}

As shown in above table-5, 53 patients out of 100 cases of atonic PPH were controlled with uterotonics. Others required additional management which included Balloon tamponade in 17 cases, Ut. Artery ligation in 9 cases, B-Lynch suture application in 8 cases and finally hysterectomy in 8 cases. In 15 cases cervical/vaginal wall tears were repaired while in 1 case vulval haematoma was drained. Traumatic PPH was managed by repair in 23 cases and out of which in 10 cases, vulval haematoma were drained. Seven cases underwent manual removal of placenta. Reposition of uterus for inversion was done in 2 cases.

\section{Discussion}

Postpartum haemorrhage (PPH) is one of the leading causes of death in women who deliver after 20 weeks of gestation. ${ }^{1}$ It is defined by the WHO as post-partum blood loss in excess of $500 \mathrm{ml}$. Blood loss during the first 24 hours after delivery is known as primary PPH, whereas blood loss from 24 hours up to 6 weeks after delivery is termed late or secondary $\mathrm{PPH}^{2,3}$ Postpartum haemorrhage remains a major cause of maternal morbidity and mortality worldwide. There are 600,000 maternal deaths reported worldwide every year and $99 \%$ of these occur in developing countries. Around $25 \%$ of deaths in developing world are due to PPH. The prevalence of PPH in India is $23 \%$. The WHO estimates that every year $25.7 \%$ maternal deaths occur in India in which PPH is most common cause of death. ${ }^{3}$ In the present study, total PPH cases were 135 and number of total deliveries were 4933 in 6 months. The incidence of PPH in was $2.73 \%$.

The maximum number of cases $(\mathrm{n}=65,48.14 \%)$ in present study were among age group of 20-24 years followed by $25-29$ years $(n=54,40.00 \%)$. Lao et al also showed in their study that aging was associated with decreasing PPH, the risk decreasing progressively from those aged $25-29$ years to those aged $\geq 40$ years compared with the 20-24years group. ${ }^{6}$ In contrast, a study by Ijaiya MA showed that the risk of PPH in advanced maternal age over 35 years was twofold higher than low maternal age $<25$ years. ${ }^{7}$

Most of the cases of PPH were P1 and P2 i.e. $\mathrm{n}=62,45.92 \%, \mathrm{n}=45,33.33 \%$. Three $(2.22 \%)$ cases were para more than 5. However, Adetoro reported that PPH was high in both primipara and grand multipara. ${ }^{8}$ Also, Ohkuchi et al found primiparity to be associated with excessive blood loss at vaginal delivery. ${ }^{9}$ But Babinszki et al showed in their study that incidence of PPH was higher in grand multiparas while Selo-Ojeme and Tsu reported that there is no association between parity and $\mathrm{PPH} .{ }^{10-11}$

Seventy six cases $(56.2 \%)$ belonged to lower middle socio-economic status followed by middle socioeconomic status 40 cases (29.6\%). Bibi et al showed in their study that patients with lower socio-economic status had more frequency of PPH compared to upper socio-economic status. ${ }^{12}$ Abdel also concluded in his study that low socio-economic status was contributory factor for PPH. ${ }^{13,14}$

In present study out of total 135 cases, 85 (62.96\%) cases had compensated haemorrhage followed by 28 cases $(20.74 \%)$ of mild degree. Nine $(6.66 \%)$ cases had moderate degree haemorrhage while $13(9.62 \%)$ of cases were found to have severe degree of haemorrhage. $87(64.44 \%)$ cases in present study were delivered inside the hospital and rest $48(35.55 \%)$ were outborn. Of the hospital deliveries $76(87.35 \%)$ were spontaneous labour and $11(12.64 \%)$ through induced labour. Maximum number of cases were atonic cases for both spontaneous labour and induced labour. The incidence of PPH after induced labour with that after spontaneous labour was compared by Brinsden. ${ }^{15}$ Normal oxytocic regimens make the uterus harder than usual for a shorter time, so that when fetus expelled the uterus become atonic and exhausted and the cervix may be damaged. In spite of the use of oxytocics in the third stage of labor the uterus that has been exposed to high doses of oxytocics al day will respond poorly to an IM or IV of the same or similar oxytocics. Their analysis showed that the incidence of PPH was increased after induction of labour; among primiparous patients the increased incidence after induced labour was nearly twice that after spontaneous labour, even when only normal deliveries were considered. These findings indicate that atonic PPH is another complication of induction. Khireddine et al found in their study that induction of labor was independently associated with a 20\% higher risk of PPH and 
A Prospective Study To Evaluate The Etiology \& Continuum Of Management Protocol ...

severe PPH in low risk parturients, regardless of the method of induction used. This excess risk was found for induction with both oxytocin and prostaglandins. The drugs used to induce labor might have a direct effect on the uterine muscle and could act as a fatigue factor (by causing supra physiological contractions) on the myometrium muscle and thus lead to postpartum atony and possibly PPH. ${ }^{16}$ However, in the present study the incidence of PPH after induced labor was high but not statistically significant.

In present study Maximum number of cases $(n=75,55.55 \%)$ were delivered by vaginal delivery, Caesarean section was performed in $(n=50,37.03 \%)$. Six cases were delivered through assisted vaginal delivery while $4(2.96 \%)$ cases needed laparotomy for ruptured uterus. Among atonic cases 46 cases followed caesarean section while 33 cases were following vaginal delivery. Traumatic cases were more following vaginal delivery (20) than any other method. Also combined atonic \& traumatic and Retained placenta/RPOCs were more after vaginal deliveries. Even in absence of abnormal placentation blood loss was higher for caesarean than vaginal delivery. According to Saha et al incidence of atonic PPH is more after caesarean delivery than vaginal delivery and same result was found in present study. ${ }^{17}$

In the present study, anaemia was found to be most common $(\mathrm{n}=44,32.5 \%)$ risk factor among cases, followed by placenta praevia $(n=14,10.3 \%)$ and previous LSCS $(n=10,7.40 \%)$. Twins and Induction of labour were found among 8 patients each, abruption in 5 cases and pre-eclampsia was risk factor among 4 cases. Among anaemic patients maximum number (20) had atonic PPH followed by traumatic PPH(12) and combined atonic \& traumatic PPH (5). In cases of atonic PPH, maximum cases were anaemic (20) followed by placenta praevia (13). For traumatic PPH also maximum number of cases were anaemic (12). Only 1 traumatic PPH case had placenta praevia. Placenta accreta and twins were found to be associated with atonic PPH only. This result was comparable to the findings of Al-Zirgi. Al-Zirgi studied that uterine atony, retained placenta and trauma were identified causes in 30, 18 and $13.9 \%$ of women respectively. The risk was higher for multiple pregnancies, von Willebrand's disease and anaemia during pregnancy. ${ }^{18}$ Ijaiya et al also studied that uterine atony is the leading cause of PPH. High parity and age related changes that occur in connective tissue and uterine muscle which diminishes the uterine contraction and retraction after delivery. The other contributory factors include overdistension of uterus and prolonged labor. Other identified causes of PPH are lower genital laceration, retained placenta and ruptured uterus.

The present study also shows that maximum number of PPH cases in PGIMS were atonic (72) while among outborn cases, traumatic (17) were in maximum numbers followed by atonic (12) and combined atonic and traumatic cases (11). Saha et al also studied that atonic PPH is most important cause. ${ }^{17}$ A study done by Bibi et al studied that uterine atony $(70.5 \%)$ is most important cause of $\mathrm{PPH}$, and traumatic lesion of genital tract $(29.4 \%)$. Factors causing uterine atony were augmented labour $(20.9 \%)$, prolonged labor $(21.9 \%)$, retained placental tissues $(12.5 \%)$, retained placenta $(11.4 \%)$ couvelliar uterus $(10.4 \%)$, placenta praevia $(8.3 \%)$, placenta incrreta $(7.3 \%)$ and multiple pregnancy $(2.1 \%) .{ }^{12}$ The factors associated with major obstetric haemorrhage were analyzed included anaemia, placental abruption, placenta praevia, multiple pregnancy, but not high parity. These data provide a more comprehensive assessment of risk factors for potentially life threatening haemorrhage. ${ }^{19}$

Anaemia was most common morbidity, found among 59(43.70\%) patients in the present study. Seven patients $(5.18 \%)$ required respiratory intensive care unit (RICU) transfer. Wound sepsis occurred in $6(4.44 \%)$ cases. These findings were similar with the findings of Ijaiya et al where postpartum anaemia was the most common complications. ${ }^{19}$ Osinaike identified obstetric haemorrhage (with uterine atony as a cause) as one of the reason for admission into the ICU. ${ }^{20}$ Admission to an intensive care unit, postpartum sepsis, hysterectomy, acute renal failure and maternal deaths were significantly more common among women with severe haemorrhage.

In present study there were 5 cases of maternal mortality out of which 2 had delivered in our hospital and 3 had delivered outside and referred to PGIMS. The minimum age of mortality was 22 years while 27 year was maximum age of mortality in present study. Lower-middle socio-economic status and multi-parity were common findings. In all inborn patients labour was spontaneous and mode of delivery was caesarean section while in cases of outborn, common mode was vaginal delivery. Atonic PPH was the cause of mortality in 2 cases while combined atonic and traumatic PPH was the cause of mortality in 3 cases. The cause of PPH was Atonic in 2 cases while Atonic+Traumatic were present in another 2 cases. All 5 patients were transfused blood and its components. Two patients were managed by Balloon tamponade along with uterotonics while in 2 patients hysterectomy was done. One patient transferred to RICU and she survived there for 7days. The common cause of death was hypovolumic shock followed by renal failure.

Current MMR of the INDIA is 174 and in present study MMR was 162 . The lower mortality in our study might be due to earlier detection of PPH by calculating exact amount of blood loss by PPH bag and active intervention both in inborn cases and cases referred from outside. Maternal death in present study was comparable with study carried out by Kaul. ${ }^{21}$ Hence, this indicates that early intervention and blood replacement even in compromised setup invariably brightens the chances of survival.

53 patients out of 100 cases of atonic PPH were controlled with uterotonics. Others required additional management which included Balloon tamponade in 17 cases, uterine artery ligation in 9 cases, B-Lynch suture application in 8 cases and finally hysterectomy in 8 cases. In 15 cases, cervical/vaginal wall tears were repaired 
A Prospective Study To Evaluate The Etiology \& Continuum Of Management Protocol ...

while in 1 case, vulval haematoma was drained. Traumatic PPH was managed by repair in 23 cases and out of which in 10 cases vulval haematoma were drained. Seven cases underwent manual removal of placenta. Reposition of uterus for inversion was done in 2 cases.

This result was compared with study by Bibi et al in which $78 \%$ cases of atonic PPH were controlled with uterotonics. Manual removal of placenta was required in $8 \%$ cases, compression sutures were applied in $2.2 \%$ and hysterectomy was required in $36.7 \%$ cases. $^{12}$

Failure of management was defined as the need to proceed to subsequent or repeat surgical or radiological therapy or hysterectomy, or death. In present study success rate of medical methods was $51.4 \%$. Burcu et al stated that first line conservative treatment modalities such as utreotonics and fundal massage were successful in $73.6 \%$ uterine atony patients. ${ }^{22}$ As balloon tamponade was the least invasive and most rapid approach, it would be logical to use this as the first step in the management. In present study Balloon tamponade was successful in $68 \%$ cases and $32 \%$ cases followed by another method. Burcu et al showed in their study that Balloon tamponade was successful in $71.4 \%{ }^{22}$ Success rate of bilateral uterine artery ligation (BIIAL) in present study was $81.81 \%$ compared to study of Kabadi YM which had efficacy of BIIAL $86.7 \% .{ }^{23}$ A study by Kaya et al showed that overall success rate of B-lynch was $75 \%$ and the overall success rate of B- lynch plus BIIAL was $94.4 \% .{ }^{24}$ Haumonte et al concluded in their study that efficacy of haemostatic brace suturing in case of failed medical treatment of PPH was about $75 \%$ while in present study B-Lynch suturing was successful in $80 \% .^{25}$

A Study done by Abdul et al showed that pharmacological options with timely transfusion of blood and plasma products, mechanical or surgical maneuvers i.e. intrauterine balloon tamponde or haemostatic brace sutures with hysterectomy as the final surgical option for uncontrollable PPH play an important role. ${ }^{26}$ Bilateral uterine artery ligation (BUAL) is easy to perform with low rate of complication.

A systematic review to evaluating the success rates of treatment of major PPH by uterine balloon tamponade, uterine compression sutures and devascularization was done. At present there was no evidence to suggest that any one method was better for the management of severe PPH.

In case of failure of conservative medical and surgical treatment, hysterectomy should be performed. ${ }^{27}$ In present study, incidence of obstetric hysterectomy due to PPH was 5.9\% (8/135) compared to Sahu et al which had $16 \%{ }^{28}$ This showed that conservative measures like uterine artery ligation, stepwise devascularization, uterine compression sutures were always tried first. If all efforts fail, obstetric hysterectomy was needed.

\section{Conclusion}

It is to conclude that primary PPH is an extremely challenging obstetric emergency associated with significant morbidity and still one of leading causes of maternal mortality. Early recognition and treatment are essential to ensure the best outcome from this life threatening condition. Though hysterectomy is the definitive treatment in women with severe PPH but in patients who desire future fertility, medical management, mechanical methods like uterine compression, uterine packing, uterine tamponade and surgical procedures like uterine artery ligation and uterine compression sutures are effective methods. All obstetricians need to be familiar with the simple technique of uterine artery ligation and compression sutures to prevent many unwarranted hysterectomies. Thus early anticipation with early intervention are required to reduce the maternal morbidity and mortality in PPH.

\section{References}

[1]. Murray SS, McKinney ES. Foundation of Maternal-Newborn and Women's Health Nursing. 5th ed. Missouri: Sounders Elsevier Publication; 2010. p.731-8.

[2]. El-Refaey H, Rodick C. Postpartum Hemorrhage: Definition, Medical and Surgical Management. A Time for Change. Br Med Bull Oxford J. 2010;96:205-17.

[3]. Yousef F, Haider G. Postpartum Hemorrhage: An experience at tertiary hospital. J Surg Pak 2009;14:2.

[4]. Armbruster D. Tackling the Biggest Maternal Killer. How the Prevention of Postpartum Hemorrhage Initiative Strengthened Effort Around the World Washington DC: 2009.

[5]. Jackson KW, Allbert JR, Schemmer GK, Elliot M, Humphrey A, Taylor J. A randomized controlled trial comparing oxytocin administration before and after placental delivery in the prevention of postpartum hemorrhage. Am J Obstet Gynecol 2001;185:873-

[6]. Lao TT, Sahota DS, Cheng YK, Law LW, Leung TY. Advanced maternal age and postpartum hemorrhage - risk factor or red herring? J Matern Fetal Neonatal Med 2014;27:242-6.

[7]. Ijaiya MA, Aboyeji AP, Abubakar D. Analysis of 348 consecutive cases of primary postpartum haemorrhage at a tertiary hospital in Nigeria. J Obstet Gynaecol 2003;23:374-7.

[8]. Adetoro OO. Primary Post Partum Haemorrhage at a University in Nigeria. West Afr J Med 1992;11:172-8.

[9]. Ohkuchi A, Onagawa T, Usui R, Koike T, Hiratsuka M, Izumi A. Effect of maternal age on blood loss during parturition: A retrospective multivariate analysis of 10,053 cases. J Perinat Med 2003;31:209-15.

[10]. Babinszki A, Kerenyi T, Torok O, Grazi V, Lapinski RH, Berkowitz RL. Perinatal outcome in grand and great-grand multiparity : effects of parity on obstetric risk factors. Am J Obstet Gynaecol 1999;181:669-74

[11]. Selo-Ojeme DO, Okonofua FE. Risk Factors for Primary Postpartum Haemorrhage. A Case Control Study. Arch Gynaecol Obstet1997;259:179-87.

[12]. Bibi S, Danish N, Fawad A, Jamil M. An audit of primary post partum hemorrhage. J Ayub Med Coll Abbottabad 2007;19:102-6 
[13]. Tsu VD. Postpartum haemorrhage in Zimbabwe: a risk factor analysis. Br J Obstet Gynaecol 2009;100:327-33.

[14]. Abdelrazik MS. Postpartum haemorrhage is a public health problem. J Egypt Soc Obstet Gynecol 1991;17:51-61

[15]. Brinsden PR, Clark AD. Postpartum haemorrhage after induced and spontaneous labour. Br Med J 1978;2:855-8.

[16]. Khireddine I. Induction of labor and risk of postpartum haemorrhage in low risk parturients. PLoS One 2013;8:548-58

[17]. Saha R. Experience with surgical options for managing atonic post partum hemorrhage, Department of obstetrics and gynaecology, Kathmandu Medical College teaching hospital, Sinamangal, Nepal. Nepal J Obstet Gynaecol 2008;3:10-3.

[18]. Al-Zirqi I, Vangen S, Forsen L, Stray PB. Prevalence and risk factors of severe obstetric haemorrhage. BJOG 2008;115:1265-72.

[19]. Stones RW, Paterso BCM, Saunders NJ. Risk factors for major obstetric haemorrhage. Eur J Obstet Gynecol Reprod 1993;48:15-8.

[20]. Osinaike B, Amanor BS, Sanusi A. Obstetric intensive care: A developing country experience. Internet J Anesthesiol 2006;10:1-6.

[21]. Kaul V, Bagga R, Jain V, Gopalan S. The impact of primary postpartum hemorrhage in near-miss morbidity and mortality in a tertiary care hospital in North India. Indian J Med Sci 2006;60:233-40.

[22]. Kasap B, Akbaba E, Oner G, Kucuk M, Akin MN, Qzturk NT, et al. Evaluation of patients with postpartum hemorrhage patients in a university - affiliated tertiary care hospital. Med Bull Haseki 2016;54:13-8.

[23]. Kabadi YM, Harsha B. Emergency internal iliac artery ligation: a conservative lifesaving procedure. Int J Reprod Contracep Obstet Gynecol 2015;4:1364-6.

[24]. Kaya B. B-Lynch uterine compression sutures in the conservative surgical management of uterine atony. Arch Gynecol Obstet 2015;291:1005-14.

[25]. Haumonte JB. Surgical treatment of postpartum haemorrhage. J Gynecol Obstet Biol Reprod 2014;43:1083-1103.

[26]. Abdul KR. Evaluation and management of postpartum haemorrhage:consensus from an international expert panel. Transfusion 2014;54:1756-68

[27]. Ducarme G, Bargy S, Grossetti A, Bougeois B, Levardon M, Luton D. Surgical management of peripartum hemorrhage: a retrospective study. Gynecol Obstet Fertil 2007;35:1209-14.

[28]. Sahu L. Hysterectomy for obstetric emergencies. J Obstet Gynaecol 2004;54:1. 